\title{
BMJ Open Characteristics of women who practice yoga in different locations during pregnancy
}

\author{
Holger Cramer, ${ }^{1,2}$ Jane Frawley, ${ }^{2}$ Amie Steel, ${ }^{2,3}$ Helen Hall, ${ }^{2,4}$ Jon Adams, ${ }^{2}$ \\ Alex Broom, ${ }^{5}$ David Sibbritt ${ }^{2}$
}

To cite: Cramer H, Frawley J, Steel $A$, et al. Characteristics of women who practice yoga in different locations during pregnancy. BMJ Open 2015;5:e008641.

doi:10.1136/bmjopen-2015008641

- Prepublication history for this paper is available online. To view these files please visit the journal online (http://dx.doi.org/10.1136/ bmjopen-2015-008641).

Received 30 April 2015 Revised 10 July 2015 Accepted 27 July 2015
CrossMark

For numbered affiliations see end of article.

Correspondence to Dr Holger Cramer; h.cramer@ kliniken-essen-mitte.de

\section{ABSTRACT}

Objectives: Yoga practice during pregnancy is gaining increasing popularity. This study examined the characteristics of pregnant women who practiced yoga in regard to the different locations (at home, in yoga classes, or both).

Design: The study sample was drawn from the Australian Longitudinal Study on Women's Health (ALSWH), a national longitudinal study of women to investigate multiple factors affecting health and wellbeing of women over a 20-year period.

Setting: Postal survey.

Participants: Women born between 1973 and 1978, who were randomly selected from the national Medicare database and identified as being pregnant or having recently given birth $(n=2316)$.

Outcome measures: Relationships between yoga use (attending yoga classes and/or practising yoga at home) and women's characteristics (demographic measures, pregnancy-related health concerns, health service utilisation, attitudes to complementary and alternative medicine).

Results: Practising yoga both at home and in classes was associated with perceiving complementary and alternative medicine (CAM) as preventative (odds ratio $(O R)=1.62)$; perceiving CAM as affording health control $(\mathrm{OR}=1.50)$; experiencing sadness $(\mathrm{OR}=1.72)$; preparing for labour $(\mathrm{OR}=2.31)$; birthing in a birth centre $(\mathrm{OR}=7.97)$; and experiencing less vomiting $(\mathrm{OR}=0.38)$. Practising at home only was associated with perceiving CAM as affording health control $(\mathrm{OR}=1.76)$; perceiving CAM as promoting a holistic health approach $(O R=1.65)$; and birthing in a birth centre $(O R=3.54)$. Practising in classes only was associated with experiencing stress $(\mathrm{OR}=1.97)$; and birthing in a birth centre $(O R=4.85)$ (all $p<0.05)$.

Conclusions: The findings suggest that the location in which a woman practices yoga is associated with attitudinal, health-related and birth environmental factors.

\section{INTRODUCTION}

Women are high adopters of complementary and alternative medicine (CAM) - generally defined as products and services that are

\section{Strengths and limitations of this study}

A strength of the reported study is the large nationally-representative sample of pregnant women.

- A further strength is the high response rate.

- The differentiation between different forms of yoga use based on location type is another strength.

- The interpretability of the findings is limited by the self-report of the respondents (introducing the possibility of recall bias).

- The specific age range (31-37 years) of the participants is a further limitation.

outside of the dominant healthcare model, with many of these treatments being used specifically for women's health issues. ${ }^{1-5}$ CAM use during pregnancy is also very popular. A recent review found that between $20 \%$ and $60 \%$ of expectant women use $\mathrm{CAM}^{2}$ and, furthermore, utilisation rates are continuing to increase. ${ }^{6}$ Pregnant women may turn to CAM for a variety of reasons, including a belief that the different CAM therapies: enable greater choice and control over their childbearing experience; offer a safe alternative reducing the need for medical intervention; provide an approach congruent with their holistic health beliefs. 78

Yoga is a common CAM used by pregnant women. ${ }^{6}{ }^{10}$ Yoga is rooted in Indian philosophy and has been a part of traditional Indian spiritual, philosophical and psychological practice for millennia. ${ }^{11}{ }^{12}$ While the original goal of yoga was to unite mind, body and spirit through ethical, spiritual and physical practices, ${ }^{11} 12$ in more contemporary practice, it is mainly regarded as a means to promote physical and mental well-being through physical postures (asanas), breathing techniques (pranayama) and meditation (dyana). ${ }^{11} 13$ These more physically oriented 
yoga forms are gaining increased popularity as a therapeutic practice, with about $9 \%$ of the American adult population reporting yoga use in 2012. Furthermore, more than two-thirds of those people using yoga did so with the explicit intention of improving their health status. ${ }^{14}$ Yoga is typically practiced in yoga classes, however, many yoga users complement these supervised sessions with unsupervised yoga practice at home; ${ }^{13}$ and almost half of American adult yoga users practiced only at home and did not attend yoga classes at all in 2012. ${ }^{14}$ This distinction with regard to location is important. On the one hand, some have suggested practising yoga without supervision from an adequately trained yoga teacher may lead to possible undesirable health outcomes such as injuries. ${ }^{15-17}$ Contrastingly, others suggest that the home practice of yoga may enhance the health benefits gained from such practice, such as pain relief. ${ }^{18}$

In a US nationally-representative survey, the typical yoga user has been shown to be female and of reproductive age. ${ }^{19}$ Likewise, $85 \%$ of Australian yoga users were reported to be female and $61 \%$ to be less than 45 years of age. ${ }^{20}$ Of these yoga users, $3 \%$ and $4 \%$ cited pregnancy as a motivation for initiating and continuing yoga practice, respectively. Further to this, between $17 \%$ and $19 \%$ of Australian women practice yoga during pregnancy. ${ }^{621}$ While antenatal yoga has been claimed to hold therapeutic benefits beyond other forms of exercise, ${ }^{22}$ the number of clinical trials investigating the effects of yoga in pregnant women remains limited; ${ }^{23} 24$ most data does, however, demonstrate a positive association between the practice of yoga and pregnancy, labour and birth outcomes.

Despite the popularity of yoga and its potential to improve infant and maternal outcomes, little is known about the characteristics of women who practice it during pregnancy. Moreover, differences between women practising yoga at home and those attending yoga classes have not been investigated. Thus, the aim of this study was to examine characteristics of pregnant women who practice yoga at home, in yoga classes or both.

\section{METHODOLOGY \\ Sample}

The study sample was drawn from the Australian Longitudinal Study on Women's Health (ALSWH). The ALSWH, which began in 1996, is a national longitudinal study of women in three cohorts ('young' born 19731978; 'mid-age' born 1946-1951; and 'older' born 19211926) who were randomly selected from the national Medicare database to investigate multiple factors affecting health and well-being of women over a 20-year period. In the Survey, five women from the 'young' cohort who were identified as being pregnant or having recently given birth $(\mathrm{n}=2316)$ were invited to participate in a substudy in 2010. The 85 item self-administered questionnaire addressed areas of health service utilisation, attitudes to CAM, health status and demographics. Ethics approval for the sub-study reported here was gained from the relevant ethics committees at the University of Queensland, University of Newcastle and University of Technology Sydney.

\section{Demographic measures}

Data on women's degree of income manageability, employment status, highest educational qualification and marital status were collected. Postcode of residence was used to classify residence as urban or non-urban.

\section{Pregnancy-related health concerns}

Information was collected on 25 common pregnancy complaints such as emotional well-being (eg, sadness, perceived stress), nausea and vomiting. Women were also asked to identify if they actively prepared for labour. The full list of health issues included in this survey has been reported elsewhere previously. ${ }^{25}$

\section{Health service utilisation}

Women provided information about their consultations with maternity care providers including general practitioners, midwives and obstetricians. Information was also collected regarding women's birth choices such as whether women decided to give birth in a private or public hospital setting, in a birth centre or at home. Women were asked to indicate if they practised yoga at home, attended classes or both. These categories were defined through responses to the following survey items: During pregnancy, how many times did you visit each of these alternative health practitioners for pregnancy-related health conditions? (response option: yoga/meditation classes); With regard to your use of the following treatments (if applicable) during the pregnancy for your youngest child specifically for pregnancy-related health issues, who prescribed these treatments?" (response option: meditation/yoga at home). For the purpose of this analysis, participants were then sorted into three groups depending on their responses to these two items: women who only identified as practising yoga at home; women who only identified as attending yoga/meditation classes; and women who identified as practising yoga/meditation at home and attending classes.

\section{Attitudes to complementary and alternative medicine}

The questionnaire included items that specifically examined women's attitudes to CAM, focusing on aspects such as its value in relation to conventional medicine, the level of control afforded by CAM use, the influence of evidence on their use of CAM, the need for testing of CAM and principles of holism within CAM care.

\section{Statistical analysis}

The women were categorised, based on their yoga use, into three categories: women who attended yoga classes and practised yoga at home; women who only practised yoga at home; and women who only attended yoga 
Table 1 Demographic characteristics of participants $(n=1835)$

\begin{tabular}{|c|c|c|}
\hline \multirow[b]{2}{*}{ Demographics } & \multicolumn{2}{|c|}{ All participants $(n=1835)$} \\
\hline & $\mathbf{n}$ & Per cent \\
\hline \multicolumn{3}{|l|}{ Area of residence } \\
\hline Urban & 1134 & 62.4 \\
\hline Rural & 629 & 34.6 \\
\hline Remote & 55 & 3.0 \\
\hline \multicolumn{3}{|l|}{ Financial status } \\
\hline Always difficult to manage on available income & 221 & 12.1 \\
\hline Sometimes difficult to manage on available income & 530 & 29.0 \\
\hline Managing on available income is not too bad & 768 & 42.1 \\
\hline Easy to manage on available income & 307 & 16.8 \\
\hline \multicolumn{3}{|l|}{ Number of children } \\
\hline None & 89 & 4.9 \\
\hline One & 697 & 38.0 \\
\hline Two & 700 & 38.2 \\
\hline Three or more & 349 & 19.0 \\
\hline \multicolumn{3}{|l|}{ Marital status } \\
\hline Never married & 21 & 1.2 \\
\hline Married/de facto & 1760 & 96.3 \\
\hline Separated/divorced/widowed & 46 & 2.5 \\
\hline \multicolumn{3}{|l|}{ Qualifications } \\
\hline Year 12 qualification or less & 292 & 16.0 \\
\hline Apprenticeship or diploma qualification & 435 & 23.9 \\
\hline University degree & 1095 & 60.1 \\
\hline \multicolumn{3}{|l|}{ Insurance status } \\
\hline Private health insurance & 1296 & 71.1 \\
\hline No private health insurance & 527 & 28.9 \\
\hline \multicolumn{3}{|l|}{ Conventional maternity health professionals } \\
\hline General practitioner & 1562 & 90.1 \\
\hline Midwife & 983 & 64.7 \\
\hline Obstetrician & 1416 & 85.2 \\
\hline \multicolumn{3}{|l|}{ Birth environment } \\
\hline Public hospital & 751 & 41.5 \\
\hline Private hospital (or private patient at public hospital) & 981 & 54.1 \\
\hline \multirow[t]{2}{*}{ Birth centre/community } & 80 & 4.4 \\
\hline & mean & SD \\
\hline Age & 34.95 & 2.30 \\
\hline
\end{tabular}

classes. Relationships between yoga use across all three categories and women's characteristics (ie, demographic, pregnancy health, health service utilisation and attitudinal items) were determined using a $\chi^{2}$ test. Based on these statistical tests, all demographic, health service utilisation, attitudinal and pregnancy health variables identified as having a $p$ value $<0.25^{26}$ were entered into individual models for each yoga use category and then a stepwise backward elimination process was employed, using a likelihood ratio test, to eventually produce the most parsimonious model. Statistical significance was set at $\mathrm{p}<0.05$. All analyses were conducted using statistical program Stata 11.2 (StataCorp, College Station, Texas, USA).

\section{RESULTS}

A total of 1835 women completed the questionnaire, generating a response rate of $79.2 \%$. Respondents lived primarily in either urban $(62.4 \%)$ or rural $(34.6 \%)$ localities. Income manageability among the respondents varied with $58.9 \%$ of women reporting it was usually or always ok to manage on available income and $41.1 \%$ reporting it was difficult some or all of the time. Almost all the women were married or in a defacto relationship $(96.3 \%)$, and most held a qualification such as an apprenticeship or diploma (23.9\%), university degree $(36.7 \%)$ or postgraduate university degree $(23.4 \%)$. Most women had private health insurance at the time of the birth of their child $(71.1 \%)$, and a private hospital $(54.1 \%)$ was a more common birth environment for their most recent birth when compared with public hospital births (41.5\%) (table 1).

Table 2 outlines the characteristics of the different subgroups of women (based on location of yoga practice) as identified through logistic regression modelling. Of all women surveyed, $172(12.1 \%)$ practised yoga at home and attended classes, $122(8.3 \%)$ practised yoga at home only and $45(3.0 \%)$ attended yoga classes only. 
Table 2 Characteristics of the different subgroups of women based on location of yoga practice

\begin{tabular}{|c|c|c|c|}
\hline & $\begin{array}{l}\text { Yoga classes and home } \\
\text { practice }(n=172 / 1420) \\
\text { OR }(95 \% \text { CI), p Value }\end{array}$ & $\begin{array}{l}\text { Yoga home practice } \\
\text { only }(n=122 / 1473) \\
\text { OR }(95 \% \mathrm{Cl}), \mathrm{p} \text { Value }\end{array}$ & $\begin{array}{l}\text { Yoga classes only }(n=45 / 1505) \\
\text { OR }(95 \% \mathrm{Cl}) \mathrm{p} \text { Value }\end{array}$ \\
\hline \multicolumn{4}{|l|}{ Demographics } \\
\hline \multicolumn{4}{|l|}{ Education } \\
\hline Year 12 & & - & \\
\hline Trade/certificate & & $2.27(1.00$ to 5.14$), p=0.050$ & \\
\hline University & & 2.54 ( 1.18 to 5.43$), p=0.016$ & \\
\hline \multicolumn{4}{|l|}{ Work } \\
\hline Full-time & - & & \\
\hline Part-time & 0.52 (0.34 to 0.80$), p=0.003$ & & \\
\hline Casual & 0.60 ( 0.29 to 1.25$), p=0.173$ & & \\
\hline Not working & 0.18 (0.10 to 0.32$), p<0.001$ & & \\
\hline \multicolumn{4}{|l|}{ Area } \\
\hline Urban & - & & \\
\hline Rural & 0.53 ( 0.34 to 0.83 ), $p=0.006$ & & \\
\hline Remote & 0.43 (0.09 to 2.02$), p=0.290$ & & \\
\hline \multicolumn{4}{|l|}{ Attitudes } \\
\hline \multicolumn{4}{|l|}{$\begin{array}{l}\text { preventative than } \\
\text { conventional medicine }\end{array}$} \\
\hline $\begin{array}{l}\text { CAM gives me more } \\
\text { control over my health/ } \\
\text { body }\end{array}$ & 1.50 ( 1.07 to 2.12 ), $\mathrm{p}=0.020$ & 1.76 (1.25 to 2.48$), p=0.001$ & \\
\hline \multicolumn{4}{|l|}{$\begin{array}{l}\text { important to me as a } \\
\text { patient }\end{array}$} \\
\hline \multicolumn{4}{|l|}{$\begin{array}{l}\text { CAM promotes a holistic } \\
\text { approach to health }\end{array}$} \\
\hline \multicolumn{2}{|l|}{$\begin{array}{l}\text { CAM needs to be tested } \\
\text { for safety/side effects }\end{array}$} & 3.27 ( 1.44 to 7.41$), p=0.005$ & \\
\hline \multicolumn{4}{|c|}{ Pregnancy health conditions } \\
\hline Sadness & $1.72(1.13$ to 2.62$), p=0.011$ & & \\
\hline Stress & & & 1.97 (1.03 to 3.77$), p=0.041$ \\
\hline Repeat vomiting & 0.38 (0.18 to 0.80$), p=0.011$ & & \\
\hline \multicolumn{3}{|l|}{ Birth environment } & \\
\hline Public hospital & - & - & - \\
\hline Private hospital & 1.30 (0.87 to 1.96$), p=0.198$ & 0.92 (0.61 to 1.40$), p=0.712$ & 2.15 (1.04 to 4.41$), p=0.038$ \\
\hline Birth centre & 7.97 (3.88 to 16.37$), p<0.001$ & 3.54 (1.70 to 7.36$), p=0.001$ & 4.85 (1.43 to 16.43$), p=0.011$ \\
\hline
\end{tabular}

Women who practised yoga at home and also attended yoga classes were less likely to have part-time employment (OR 0.52, $\mathrm{p}=0.003$ ) or to be unemployed (OR $0.18, \mathrm{p}<0.001)$ compared with other women. The women identified as attending classes and practising yoga at home were also less likely to be living in a rural location (OR 0.53, $\mathrm{p}=0.006$ ) compared with women not engaging in both or either of these practices. This particular subgroup of women were more likely to perceive CAM as being better at prevention than conventional medicine (OR 1.62, $\mathrm{p}=0.004$ ), affording them more control over their health or body (OR 1.50, $\mathrm{p}=0.02$ ). Women using yoga in home and class settings were more likely than other women to report experiencing sadness during their pregnancy (OR 1.72, $\mathrm{p}=0.011)$ and identified as preparing for labour (OR 2.31, $\mathrm{p}<0.001$ ), but were less likely to have experienced repeated vomiting (OR 0.38, $\mathrm{p}=0.011$ ). Women using yoga in home and class settings were also more likely to have birthed their most recent baby in a birth centre (OR 7.97, p<0.001).

Women who only practised yoga at home and did not attend yoga classes were much more likely to have attained an apprenticeship or diploma (OR 2.27, $\mathrm{p}=0.003$ ), or had university level education (OR 2.54, $\mathrm{p}=0.016$ ) when compared with other women. Women only undertaking yoga practice at home were also more likely to perceive CAM as: affording them more control over their health and body (OR 1.76, $\mathrm{p}=0.001$ ); promoting a more holistic approach to health (OR 1.65, $\mathrm{p}=0.019$ ); needing to be tested for safety and side effects 
(OR 3.27, $\mathrm{p}=0.005)$. Women only undertaking yoga practice at home were also more likely to report having given birth in a birth centre for their most recent pregnancy (OR 3.54, $\mathrm{p}=0.001$ ). Women who were identified as only attending yoga classes, and not practising yoga at home, were more likely to report experiencing stress during their pregnancy (OR 1.97, $\mathrm{p}=0.04$ ) and birthing their most recent child in a birth centre (OR 4.85, $\mathrm{p}=0.011$ ) when compared with other women.

\section{DISCUSSION}

This survey, conducted among a large, nationally-representative sample of pregnant Australian women, found evidence that using yoga during pregnancy was associated with location of practice as well as certain demographic, attitudinal, health and birth environmental characteristics. The findings that women using yoga during pregnancy were more likely to have higher education and live in urban areas, are in line with studies examining yoga use among the general population $^{19}$ and among patients with chronic diseases. ${ }^{27}$

Interestingly, using yoga at home-either as the only form of practice or in conjunction with attending yoga classes-was associated with women's perceptions of CAM as affording them more control over their health or body while only attending classes was not associated with this perception of CAM. Compared to some other CAM modalities, using yoga requires a relatively strong initiative and motivation. The belief that yoga enables pregnant women more influence over their well-being touches on the issue of health locus of control. ${ }^{28} 29 \mathrm{An}$ individual's belief about control of health outcomes can be classified as either internal (outcomes depend on the individual's own behaviour) or external (outcomes depend on the behaviour of other people, fate or luck). ${ }^{30}{ }^{31}$ It has been shown that an internal health locus of control is associated with carrying out recommended health behaviour including taking exercise. ${ }^{32} 33$ Likewise, patients with a strong internal health locus of control have been shown to be more likely to use yoga or meditation to improve their medical condition, while those with a strong external health locus of control are less likely to use yoga. ${ }^{27} 34$ The findings of our study suggest that this association might mainly apply to those individuals practising yoga at home. It is likely that the health outcomes of attending supervised yoga classes might be perceived to also depend on the behaviour of other people such as the yoga teacher or other class attendants. Thus, restricting the use of yoga to their home might mainly attract women with a strong internal health locus of control while attending yoga classes does not seem to depend on health locus of control. The impact of frequency of yoga practice/class attendance was not examined in this analysis and would benefit from future research attention.

Women attending yoga classes-either as the only form of practice or in conjunction with at-home practice -were more likely to report experiencing sadness or stress, while those only practising at home were not. This is in line with findings from previous research showing people using yoga are more likely to suffer from mental health conditions than those not using yoga, in the general population ${ }^{19}{ }^{35}$ and in specific patient populations. ${ }^{27}$ Yoga has also been shown to improve depression in depressed individuals. ${ }^{36}$ A number of clinical trials have also demonstrated psychological benefits within the pregnant population: the use of yoga during pregnancy is associated with improvements in perinatal stress, anxiety and depression, ${ }^{37-41}$ and there is also evidence that yoga use can lead to improved sleep, ${ }^{37}$ quality of life $^{42}$ and interpersonal relationships. ${ }^{42}$ Given these circumstances, it appears more likely that women experiencing sadness and stress during pregnancy may be attracted to undertaking yoga as a means by which to address these negative experiences rather than yoga use during pregnancy causing the stress and sadness. Another explanation for why women attending yoga classes were more likely to experience sadness and stress would be that women using yoga only at home may have integrated the core values of yoga more meaningfully into their daily lives, which may be improving their mental health. This interpretation is in line with our finding that women solely using yoga at home (and not in classes) were the only respondents more likely to perceive CAM as promoting a holistic approach to health.

Similarly, the finding that women using yoga both at home and via yoga classes were less likely to experience repeated vomiting during pregnancy could be interpreted in two ways. Although there is no evidence that yoga can reduce vomiting related to pregnancy, it has been shown that yoga can improve treatment-related vomiting in women suffering from breast cancer. ${ }^{43} 44$ Thus, pregnancy-related vomiting might also be reduced in women using yoga during pregnancy. However, it has also been shown that women experiencing vomiting during pregnancy are less likely to use any form of exercise, ${ }^{45}$ and it may be that vomiting could also limit yoga use during pregnancy.

Our analyses revealed that women attending yoga classes as well as practising at home were more likely to actively prepare for labour and birth than women not engaging in both or either of these practices. Moreover, women attending yoga classes and practising at home were also more likely than other women to perceive CAM as offering better prevention than conventional medicine. As such, yoga and other CAM use might be components of wider initiatives via which these women actively prepare for labour. The decision to use yoga as a preparation for labour might be driven by claims that practising yoga postures and breathing techniques during pregnancy improve flexibility and lead to a more calm and relaxed state of mind, resulting in a more satisfying birth. ${ }^{46}$ These claims are at least partly supported by randomised clinical trials showing that the use of yoga during pregnancy is associated with a decrease in labour pain and duration, and an increase in birthing confidence. ${ }^{47} 48$ 
All forms of yoga use (based on location types) were strongly associated with birthing in a birth centre (compared to birthing in a private or public hospital). Midwives hold significant influence over the maternity care provided within a birth centre and they have been shown to generally promote natural childbirth, empowerment of women and holistic care. ${ }^{49}$ The research indicates that midwives' support for CAM is exceptionally high. ${ }^{50}$ It is thus likely that women planning to birth in a birth centre are encouraged by their midwives to use yoga; and this recommendation can be preliminarily regarded as evidence-based. In addition to the benefits to women's perinatal mental health and birth satisfaction, yoga use during pregnancy is associated with improvements in gestational diabetes, ${ }^{51}$ a reduced incidence of preterm labour, pregnancy-induced hypertension and intrauterine growth retardation,,$^{52} 53$ and amelioration of various pregnancy-related discomforts such as back pain, varicose veins, haemorrhoids and fatigue. ${ }^{48}$ However, yoga use has also been associated with certain risks such as ligament tears, fractures, neuropathy and even stroke. ${ }^{1516}$ These risks should be considered when giving recommendations about yoga use during pregnancy.

The strengths of the reported study include the large nationally-representative sample of pregnant women, a high response rate and the differentiation between different forms of yoga use based on location type. However, the interpretability of the findings is limited by the self-report of the respondents (introducing possibility of recall bias) as well as the specific age range (3137 years) of the participants. The cross-sectional design limits the interpretation of causal relationships between yoga use, mood and vomiting related to pregnancy. It also limits the ability to consider the role of previous health behaviours (including historical yoga practice) in influencing or characterising use. Our understanding would benefit from future research that investigates the characteristics of yoga users in pregnant women of younger age groups.

\section{CONCLUSION}

Our findings suggest that the use of the three different forms of yoga use based on location types is associated with their own demographical, attitudinal, health-related and birth environmental factors. Attitudes towards CAM and pregnancy-related health outcomes seem to be strongly associated with yoga use during pregnancy. Moreover, it seems likely that many pregnant women choose to use yoga due to a recommendation from a midwife. Given that yoga might positively influence pregnancy-related health issues and birth outcomes, but can also be associated with certain risks, it is important that obstetricians and midwives be cognisant of potential yoga use among pregnant women and actively discuss if and where (at home, in class, or both) yoga should be used to help ensure safe, effective maternity care.
Author affiliations

${ }^{1}$ Department of Internal and Integrative Medicine, Kliniken Essen-Mitte, Faculty of Medicine, University of Duisburg-Essen, Essen, Germany

${ }^{2}$ Faculty of Health, Australian Research Centre in Complementary and Integrative Medicine (ARCCIM), University of Technology Sydney, Sydney, New South Wales, Australia

${ }^{3}$ Endeavour College of Natural Health, Brisbane, Queensland,

Australia

${ }^{4}$ School of Nursing \& Midwifery, Monash University, Frankston, Victoria, Australia

${ }^{5}$ Faculty of Arts and Social Sciences, School of Social Sciences, University of New South Wales, Sydney, Australia

Acknowledgements The research on which this paper is based was conducted as part of the Australian Longitudinal Study on Women's Health, The University of Newcastle and The University of Queensland. The authors are grateful to the Australian Government Department of Health and Ageing (DOHA) for funding and to the women who provided the survey data.

Contributors DS, AB and JA designed the study. DS analysed the data. HC, $\mathrm{JF}$ and AS interpreted the data and drafted the manuscript. All the authors contributed to the editing and writing of the manuscript, and approved the final manuscript.

Funding This work was supported by Australian Research Council (ARC), Discovery Project Funding (DP1094765)

Competing interests None declared.

Ethics approval Ethics committees at the University of Queensland, University of Newcastle and University of Technology Sydney.

Provenance and peer review Not commissioned; externally peer reviewed.

Data sharing statement No additional data are available.

Open Access This is an Open Access article distributed in accordance with the Creative Commons Attribution Non Commercial (CC BY-NC 4.0) license, which permits others to distribute, remix, adapt, build upon this work noncommercially, and license their derivative works on different terms, provided the original work is properly cited and the use is non-commercial. See: http:// creativecommons.org/licenses/by-nc/4.0/

\section{REFERENCES}

1. Adams J, Sibbritt DW, Easthope G, et al. The profile of women who consult alternative health practitioners in Australia. Med J Aust 2003;179:297-300.

2. Adams J, Lui CW, Sibbritt D, et al. Women's use of complementary and alternative medicine during pregnancy: a critical review of the literature. Birth 2009;36:237-45.

3. Bishop FL, Lewith GT. Who Uses CAM? A Narrative Review of Demographic Characteristics and Health Factors Associated with CAM Use. Evid Based Complement Alternat Med 2010;7:11-28.

4. Conboy L, Patel S, Kaptchuk TJ, et al. Sociodemographic determinants of the utilization of specific types of complementary and alternative medicine: an analysis based on a nationally representative survey sample. J Altern Complement Med 2005;11:977-94.

5. Steel A, Adams J, Sibbritt D, et al. The influence of complementary and alternative medicine use in pregnancy on labor pain management choices: results from a nationally representative sample of 1,835 women. J Altern Complement Med 2014;20:87-97.

6. Adams J, Sibbritt D, Lui CW. The use of complementary and alternative medicine during pregnancy: a longitudinal study of Australian women. Birth 2011;38:200-6.

7. Hall HG, Griffiths DL, McKenna LG. The use of complementary and alternative medicine by pregnant women: a literature review. Midwifery 2011;27:817-24.

8. Mitchell M, McClean S. Pregnancy, risk perception and use of complementary and alternative medicine. Health Risk Soc 2014;16:101-16.

9. Furlow ML, Patel DA, Sen A, et al. Physician and patient attitudes towards complementary and alternative medicine in obstetrics and gynecology. BMC Complement Altern Med 2008;8:35.

10. Hall HR, Jolly K. Women's use of complementary and alternative medicines during pregnancy: a cross-sectional study. Midwifery 2014;30:499-505. 
11. Feuerstein G. The yoga tradition. Prescott: Hohm Press, 1998.

12. lyengar BKS. Light on yoga. New York: Schocken Books, 1966.

13. De Michelis E. A history of modern yoga: patanjali and western esotericism. London, UK: Continuum International Publishing Group, 2005.

14. Zhang $Y$. American adult yoga practice: preliminary findings from NHIS 2012 data. J Altern Complement Med 2014;20:A122.

15. Cramer H, Krucoff C, Dobos G. Adverse events associated with yoga: a systematic review of published case reports and case series. PLOS ONE 2013;8:e75515.

16. Fishman LM, Saltonstall E, Genis S. Understanding and preventing yoga injuries. Int J Yoga Therap 2009;19:47-54.

17. Cramer H, Ward L, Saper R, et al. The safety of yoga: a systematic review and meta-analysis of randomized controlled trials. $\mathrm{Am} \mathrm{J}$ Epidemiol 2015;182:281-93.

18. Tilbrook HE, Cox H, Hewitt CE, et al. Yoga for chronic low back pain: a randomized trial. Ann Intern Med 2011;155:569-78.

19. Birdee GS, Legedza AT, Saper RB, et al. Characteristics of yoga users: results of a national survey. J Gen Intern Med 2008;23:1653-8.

20. Penman S, Cohen M, Stevens P, et al. Yoga in Australia: results of a national survey. Int $J$ Yoga 2012;5:92-101.

21. Steel A, Adams J, Sibbritt D, et al. Relationship between complementary and alternative medicine use and incidence of adverse birth outcomes: an examination of a nationally representative sample of 1835 Australian women. Midwifery 2014;30:1157-65.

22. Collins C. Yoga: intuition, preventive medicine, and treatment. J Obstet Gynecol Neonatal Nurs 1998;27:563-8.

23. Babbar S, Parks-Savage AC, Chauhan SP. Yoga during pregnancy: a review. Am J Perinatol 2012;29:459-64.

24. Curtis K, Weinrib A, Katz J. Systematic review of yoga for pregnant women: current status and future directions. Evid Based Complement Alternat Med 2012;2012:715942.

25. Steel A, Adams J, Sibbritt D, et al. Utilisation of complementary and alternative medicine (CAM) practitioners within maternity care provision: results from a nationally representative cohort study of 1,835 pregnant women. BMC Pregnancy Childbirth 2012;12:146.

26. Hosmer DW, Lemeshow S. Introduction to logistic regression. London: John Wiley \& Sons, 1989.

27. Cramer $\mathrm{H}$, Lauche $\mathrm{R}$, Langhorst J, et al. Predictors of yoga use among internal medicine patients. BMC Complement Altern Med 2013;13:172.

28. Ewart CK, Taylor CB, Reese LB, et al. Effects of early postmyocardial infarction exercise testing on self-perception and subsequent physical activity. Am J Cardiol 1983;51:1076-80.

29. Rotter JB. Generalized expectancies for internal vs. external control of reinforcement. Psychol Monogr 1966;80:1-28.

30. Wallston KA. Control and health. In: Anderson A, ed. Encyclopedia of health \& behavior. Vol 1. Thousand Oaks: Sage, 2004:217-20.

31. Wallston KA. Multidimensional health locus of control scale. In: Christensen AJ, Martin R, Smyth J, eds. Encyclopedia of health psychology. New York: Kluwer/Plenum, 2004:171-2.

32. Norman $\mathrm{P}$, Bennett $\mathrm{P}$, Smith $\mathrm{C}$, et al. Health locus of control and leisure-time exercise. Personal Individ Differ 1997:23:769-74.

33. Slenker SE, Price JH, O'Connell JK. Health locus of control of joggers and nonexercisers. Percept Mot Skills 1985;61:323-8.

34. Cramer $\mathrm{H}$, Lauche $\mathrm{R}$, Langhorst $\mathrm{J}$, et al. Characteristics of patients with internal diseases who use relaxation techniques as a coping strategy. Complement Ther Med 2013;21:481-6.
35. Adams J, Sibbritt D, Lui CW. Health service use among persons with self-reported depression: a longitudinal analysis of 7,164 women. Arch Psychiatr Nurs 2012;26:181-91.

36. Cramer $\mathrm{H}$, Lauche $\mathrm{R}$, Langhorst J, et al. Yoga for depression: a systematic review and meta-analysis. Depress Anxiety 2013;30:1068-83

37. Beddoe AE, Lee KA, Weiss SJ, et al. Effects of mindful yoga on sleep in pregnant women: a pilot study. Biol Res Nurs 2010;11:363-70.

38. Field T, Diego M, Delgado J, et al. Yoga and social support reduce prenatal depression, anxiety and cortisol. J Bodyw Mov Ther 2013;17:397-403.

39. Field T, Diego M, Hernandez-Reif M, et al. Yoga and massage therapy reduce prenatal depression and prematurity. J Bodyw Mov Ther 2012;16:204-9.

40. Newham JJ, Wittkowski A, Hurley J, et al. Effects of antenatal yoga on maternal anxiety and depression: a randomized controlled trial. Depress Anxiety 2014;31:631-40.

41. Satyapriya M, Nagendra HR, Nagarathna R, et al. Effect of integrated yoga on stress and heart rate variability in pregnant women. Int J Gynaecol Obstet 2009;104:218-22.

42. Rakhshani A, Maharana S, Raghuram N, et al. Effects of integrated yoga on quality of life and interpersonal relationship of pregnant women. Qual Life Res 2010;19:1447-55.

43. Raghavendra RM, Nagarathna R, Nagendra HR, et al. Effects of an integrated yoga programme on chemotherapy-induced nausea and emesis in breast cancer patients. Eur J Cancer Care (Engl) 2007; 16:462-74.

44. Vadiraja SH, Rao MR, Nagendra RH, et al., Effects of yoga on symptom management in breast cancer patients: a randomized controlled trial. Int J Yoga 2009;2:73-9.

45. Foxcroft KF, Rowlands IJ, Byrne NM, et al, BAMBINO group. Exercise in obese pregnant women: the role of social factors, lifestyle and pregnancy symptoms. BMC Pregnancy Childbirth 2011;11:4

46. Swann S. Active birth yoga https://www.yogababy.com.au/links/ articles/active-birth-yoga/

47. Chuntharapat S, Petpichetchian W, Hatthakit U. Yoga during pregnancy: effects on maternal comfort, labor pain and birth outcomes. Complement Ther Clin Pract 2008:14:105-15.

48. Sun $Y C$, Hung $Y C$, Chang $Y$, et al. Effects of a prenatal yoga programme on the discomforts of pregnancy and maternal childbirth self-efficacy in Taiwan. Midwifery 2010;26:e31-6.

49. Adams J, Lui CW, Sibbritt D, et al. Attitudes and referral practices of maternity care professionals with regard to complementary and alternative medicine: an integrative review. J Adv Nurs 2011;67:472-83.

50. Ernst E, Watson LK. Midwives' use of complementary/alternative treatments. Midwifery 2012;28:772-7.

51. Youngwanichsetha S, Phumdoung S, Ingkathawornwong T. The effects of mindfulness eating and yoga exercise on blood sugar levels of pregnant women with gestational diabetes mellitus. Appl Nurs Res 2014;27:227-30.

52. Narendran S, Nagarathna R, Gunasheela S, et al. Efficacy of yoga in pregnant women with abnormal Doppler study of umbilical and uterine arteries. J Indian Med Assoc 2005;103:12-14, 16-17.

53. Narendran S, Nagarathna R, Narendran V, et al. Efficacy of yoga on pregnancy outcome. J Altern Complement Med 2005;11:237-44. 